Supporting Information for

\title{
Synthesis and Characterization of Unsaturated Biobased-Polyamides from Plant Oil
}

\author{
Reza Ahmadi and Aman Ullah*
}

Utilization of Lipids-Polymers/Materials Chemistry Research Group, Department of Agricultural, Food, and Nutritional Science, 4-10 Agriculture/Forestry Centre, University of Alberta, Edmonton, Alberta, Canada T6G 2P5.

* Corresponding author: Aman Ullah, E-mail: ullah2@, ualberta.ca

Tel: +1 (780) 492-4845, Fax: +1(780) 492-4265

Number of pages: 10

Number of schemes: 2

Number of tables: 1

Number of figures: 10 


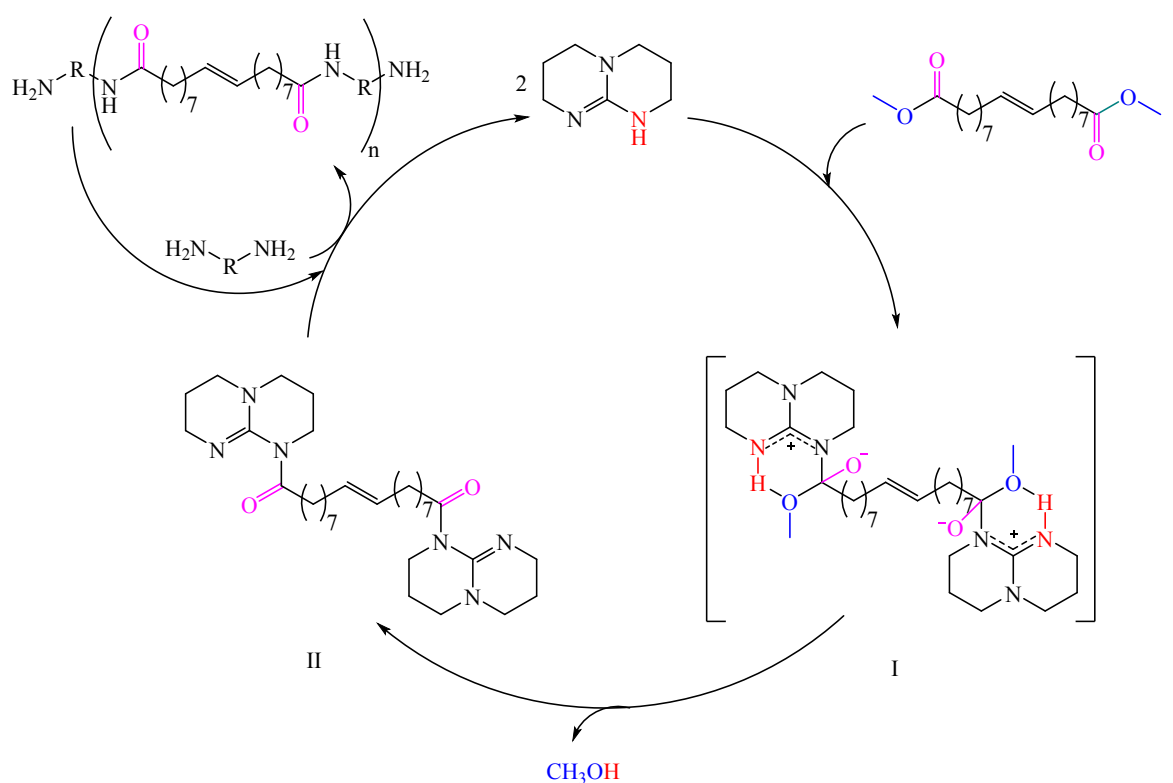

Scheme S1) Polycondensation mechanism of biobased diester (DMOD) with amines (PXDA or DETA) by TBD catalyst.

a)

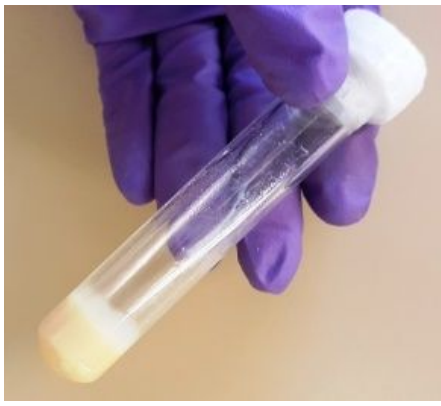

b)

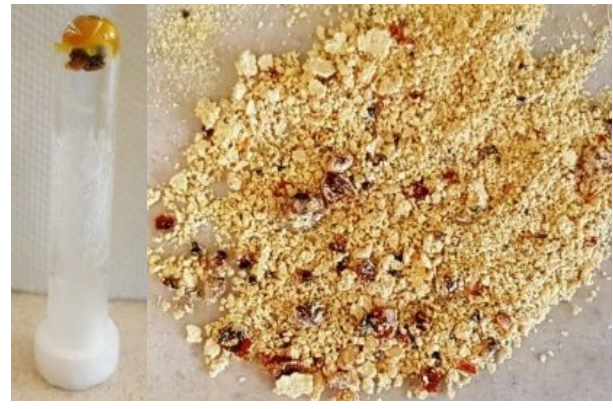

Figure S1. Polycondensation of PA (DMOD-PXDA) under microwave irradiation. the representatives of a) a successful reaction and b) an unsuccessful reaction.
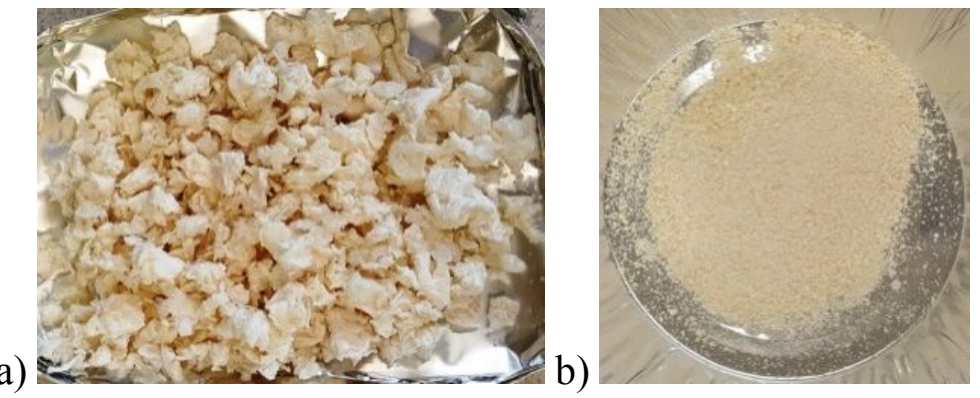

Figure S2. Representative semi-aromatic biobased PAs (DMOD-PXDA), (a) after precipitation in cold methanol and, (b) after crushing and washing. 
Nuclear Magnetic Resonance (NMR) Analysis. A Varian Inova spectrometer (Varian, CA) was used to collect the ${ }^{1} \mathrm{H}$ NMR spectra of sample at $400 \mathrm{MHz}$ and $25.9^{\circ} \mathrm{C}$. Almost $35 \%$ of the polyamide resulted from DMOD and PXDA after 8 min microwave irradiation was dissolved in deuterated chloroform $\left(\mathrm{CDCl}_{3}\right)$ with the help of TFAA.

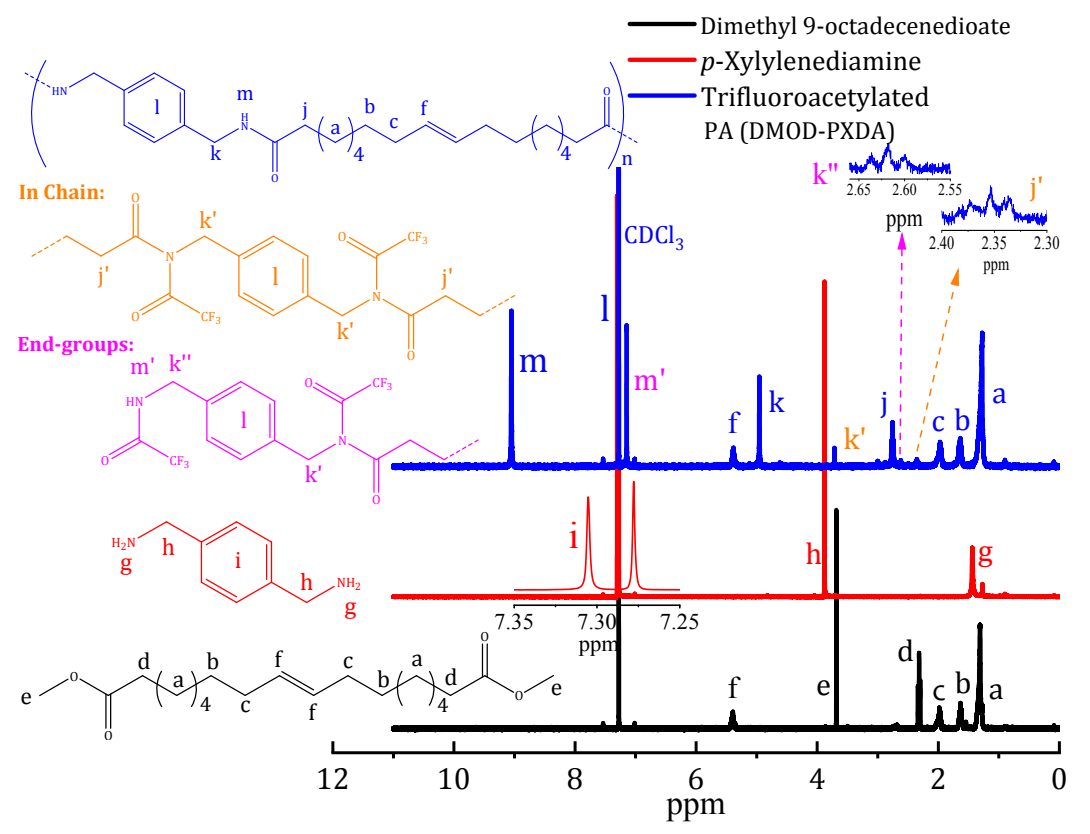

Figure S3. Representative ${ }^{1} \mathrm{H}$ NMR spectra of dimethyl 9-octadecenedioate, $p$-Xylylenediamine, and the 35\% dissolvable polyamide resulted from microwave irradiation of DMOD and PXDA for 8 min.
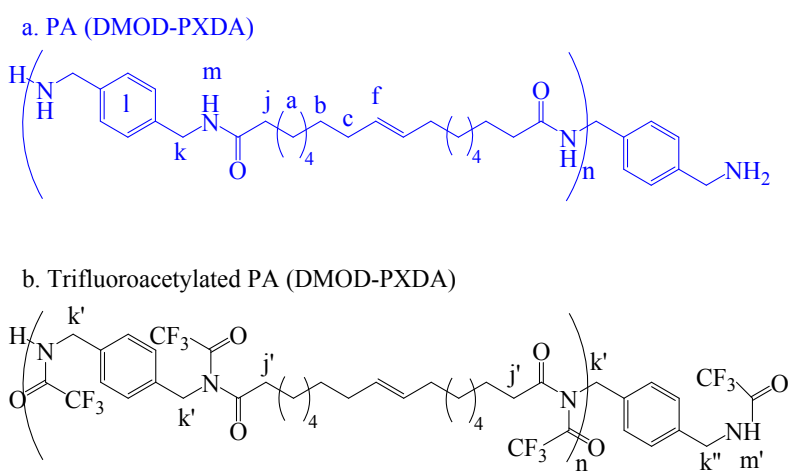

Scheme S2. a. The suggested structure and b) trifluoroacetylated structure of the $35 \%$ dissolvable polyamide resulted from microwave irradiation of DMOD and PXDA. 


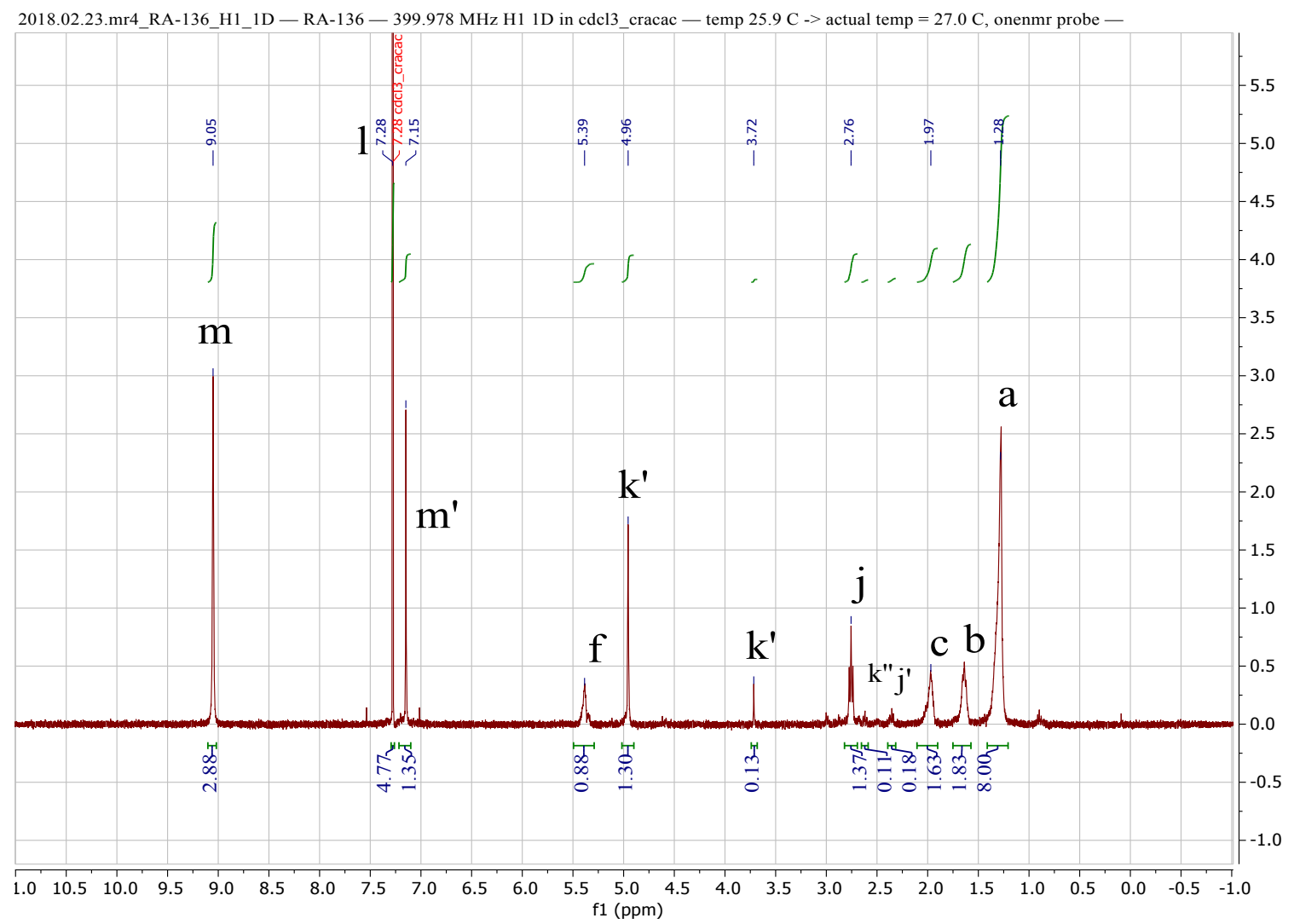

Figure S4. Representative ${ }^{1} \mathrm{H}$ NMR spectra of dimethyl 9-octadecenedioate, $p$-Xylylenediamine, and the 35\% dissolvable polyamide resulted from microwave irradiation of DMOD and PXDA for 8 min.

Table $\mathrm{S} 1$. The resulted table from the ${ }^{1} \mathrm{HNMR}$ of the $35 \%$ dissolvable polyamide resulted from microwave irradiation of DMOD and PXDA for 8 min.

\begin{tabular}{lcccc}
\hline Peak & ppm & Intensity & Width & Area \\
\hline $\mathrm{m}$ & 9.05 & 3.0 & 4.60 & 272.13 \\
$\mathrm{l}$ & 7.28 & 20.7 & 0.51 & 216.65 \\
3 & 7.28 & 18.2 & 0.58 & 243.80 \\
$\mathrm{~m}$, & 7.15 & 2.8 & 2.05 & 117.93 \\
$\mathrm{f}$ & 5.39 & 0.3 & 12.90 & 90.36 \\
$\mathrm{k}$ & 4.96 & 1.7 & 3.30 & 114.70 \\
$\mathrm{k}$, & 3.72 & 0.3 & 1.98 & 14.64 \\
$\mathrm{j}$ & 2.76 & 0.8 & 3.52 & 60.60 \\
$\mathrm{k}$, & 2.62 & 0.1 & 2.93 & 3.94 \\
$\mathrm{j}$, & 2.35 & 0.1 & 2.35 & 4.64 \\
$\mathrm{c}$ & 1.97 & 0.4 & 18.85 & 178.97 \\
$\mathrm{~b}$ & 1.64 & 0.5 & 19.11 & 175.55 \\
$\mathrm{a}$ & 1.28 & 2.3 & 9.73 & 438.64 \\
\hline
\end{tabular}


The ${ }^{1} \mathrm{H}$ NMR studies of the $35 \%$ dissolvable polyamide resulted from microwave irradiation of DMOD and PXDA for 8 min were conducted in the $\mathrm{CDCl}_{3} / \mathrm{TFAA}$ solvent mixture. TFAA reacts with the amide and amino end-groups leadings to their $\mathrm{N}$-acylation which consequently, breaks hydrogen bonds between polymer chains leading to finally solubilization of the polyamide. ${ }^{1}$ Typical ${ }^{1} \mathrm{H}$ NMR spectra of trifluoroacetylated MH-PA (DMOD-PXDA) and their monomers are presented in Figure S3, where peak assignments were based on the literature data. ${ }^{1,2}$ The characteristic signals of DMOD bio-diester were identified at $3.68 \mathrm{ppm}$ and 5.39 ppm, corresponding to the protons of the methyl end-groups (e) and the double bond (f) of the bio-diester, respectively. PXDA also exhibited clear signals at $1.44 \mathrm{ppm}$ and $7.31 \mathrm{ppm}$ matching its primary amino end-groups (g) and phenol group (i), respectively. The signal for the phenolic protons at $7.31 \mathrm{ppm}$ (i) in the spectrum of PXDA appeared close to that of the solvent $\mathrm{CDCl}_{3}$ at $7.28 \mathrm{ppm}$. The signals of the diester's methyl groups at 3.68 (e) and diamine's amino end-groups at $1.44 \mathrm{ppm}$ (g) were disappeared in MH-PA (DMOD-PXDA) spectra with the appearance of a signal at $9.05 \mathrm{ppm}$ related to amide groups (m). Furthermore, the peak related to the methylene groups in $\alpha$ position to the carbonyl groups of bio-diester (d) experienced two shifts towards the down-field in the ${ }^{1} \mathrm{H}$ NMR spectrum of the partly trifluoroacetylated biobased polyamides; the first shift from $2.32 \mathrm{ppm}(\mathrm{d})$ to $2.76 \mathrm{ppm}(\mathrm{j})$ and the second shift to $2.35 \mathrm{ppm}(\mathrm{j}$ ') due to the formation of trifluoroacetylated amide linkages. The peak of phenolic protons was also shifted from $7.31 \mathrm{ppm}$ (i) to $7.28 \mathrm{ppm}$ (1) in the spectrum of MH-PA (DMOD-PXDA). Additionally, the signal corresponding to the methylene group of PXDA at $3.88 \mathrm{ppm}$ (h) experienced different shifts due to shielding effects in the structure of trifluoroacetylated semi-aromatic polyamides. This signal was moved towards down-field region at $4.96 \mathrm{ppm}(\mathrm{K})$, while its counterparts beside the trifluoroacetylated amide group inside the polymer chain and amino end-groups of polymer 
were shielded more and appeared at $3.72 \mathrm{ppm}\left(\mathrm{K}^{\prime}\right)$ and $2.62 \mathrm{ppm}\left(\mathrm{k}^{\prime \prime}\right)$, respectively. The trifluoroacetylated amino end-groups of the semi-aromatic polyamides were also identified at $7.15 \mathrm{ppm}\left(\mathrm{m}^{\prime}\right)$.

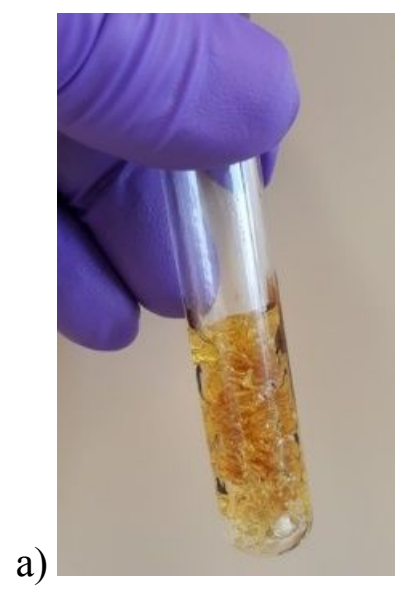

b)

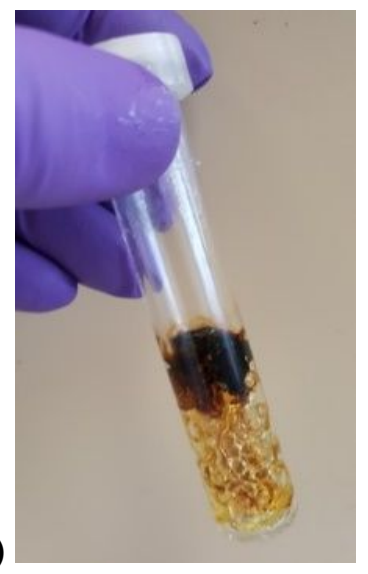

Figure S5. Polycondensation of PA (DMOD-DETA) under microwave irradiation. The representatives of a) a successful reaction and b) an unsuccessful reaction.

a)

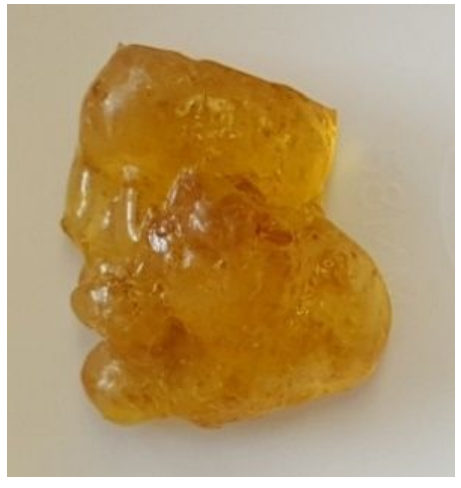

b)

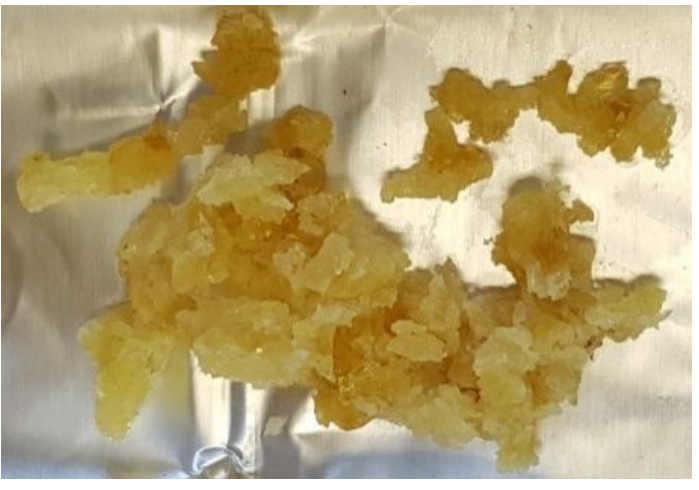

Figure S6. Representative aliphatic biobased PAs (DMOD-DETA) before (a) and after (b) washing. 
DETA):

\section{Peak Analysis}

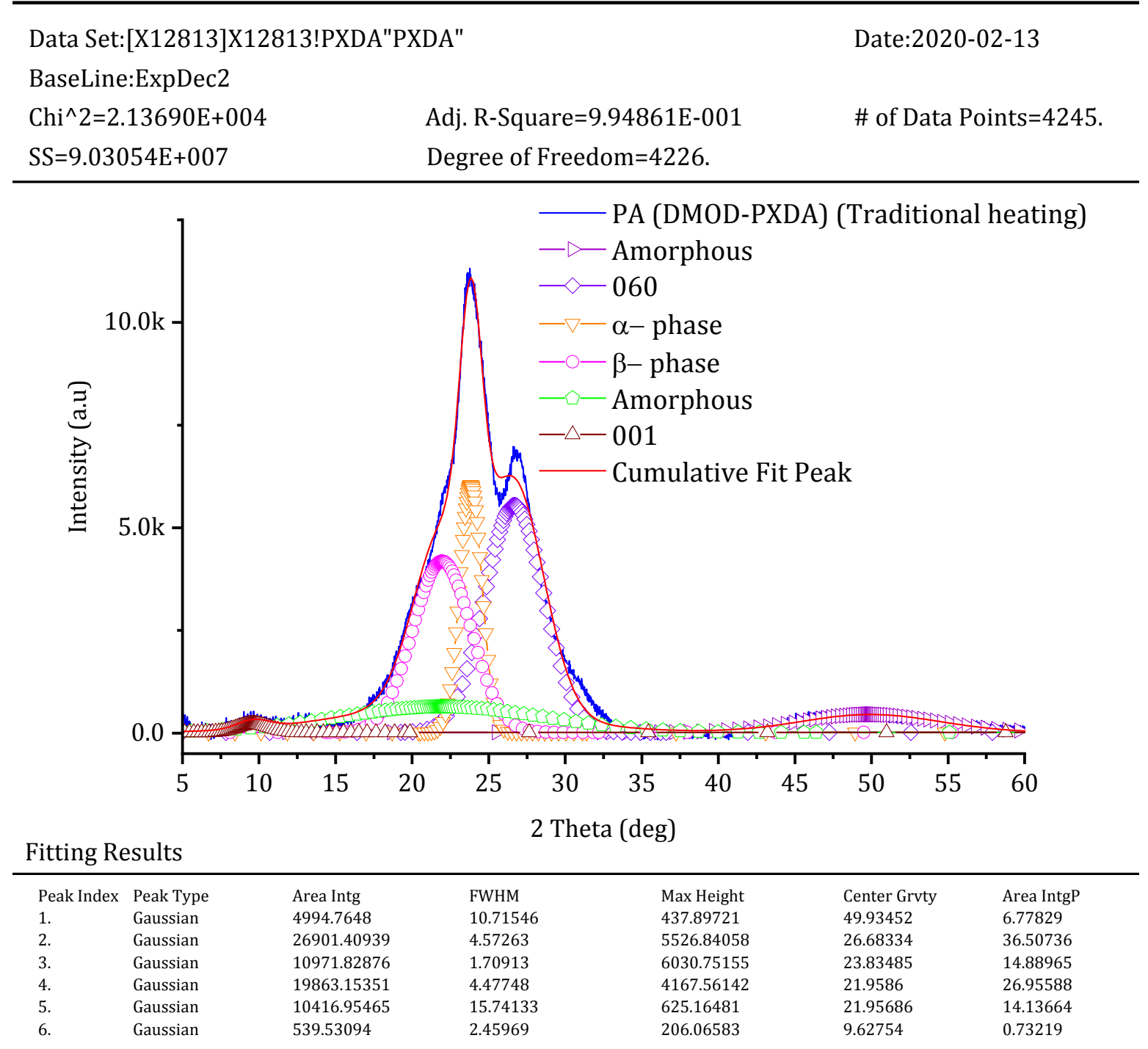

Figure S7. The profile fittings of biobased TH-PA (DMOD-PXDA).

Peaks:

1-Amorphous, 2-060, 3- $\alpha$-phase, 4- $\beta$-phase, 5- Amorphous, 6- 001 


$$
x_{c, W A X D}=\left(\frac{\sum A_{\text {Crystal }}}{\sum A_{\text {Crystal }}+\sum A_{\text {Amorphous }}}\right) \times 100=\left(\frac{58257.8}{73687.5}\right) \times 100=79.1 \%
$$

\section{Peak Analysis}

\begin{tabular}{|c|c|c|}
\hline \multicolumn{2}{|l|}{ Data Set:[X12451]X12451!B } & Date:2020-02-13 \\
\hline \multicolumn{3}{|l|}{ BaseLine:ExpDec2 } \\
\hline $\mathrm{Chi}^{\wedge} 2=7.33322 \mathrm{E}+003$ & Adj. R-Square=9.91132E-001 & \# of Data Points=4251. \\
\hline$S S=3.10562 E+007$ & Degree of Freedom=4235. & \\
\hline
\end{tabular}

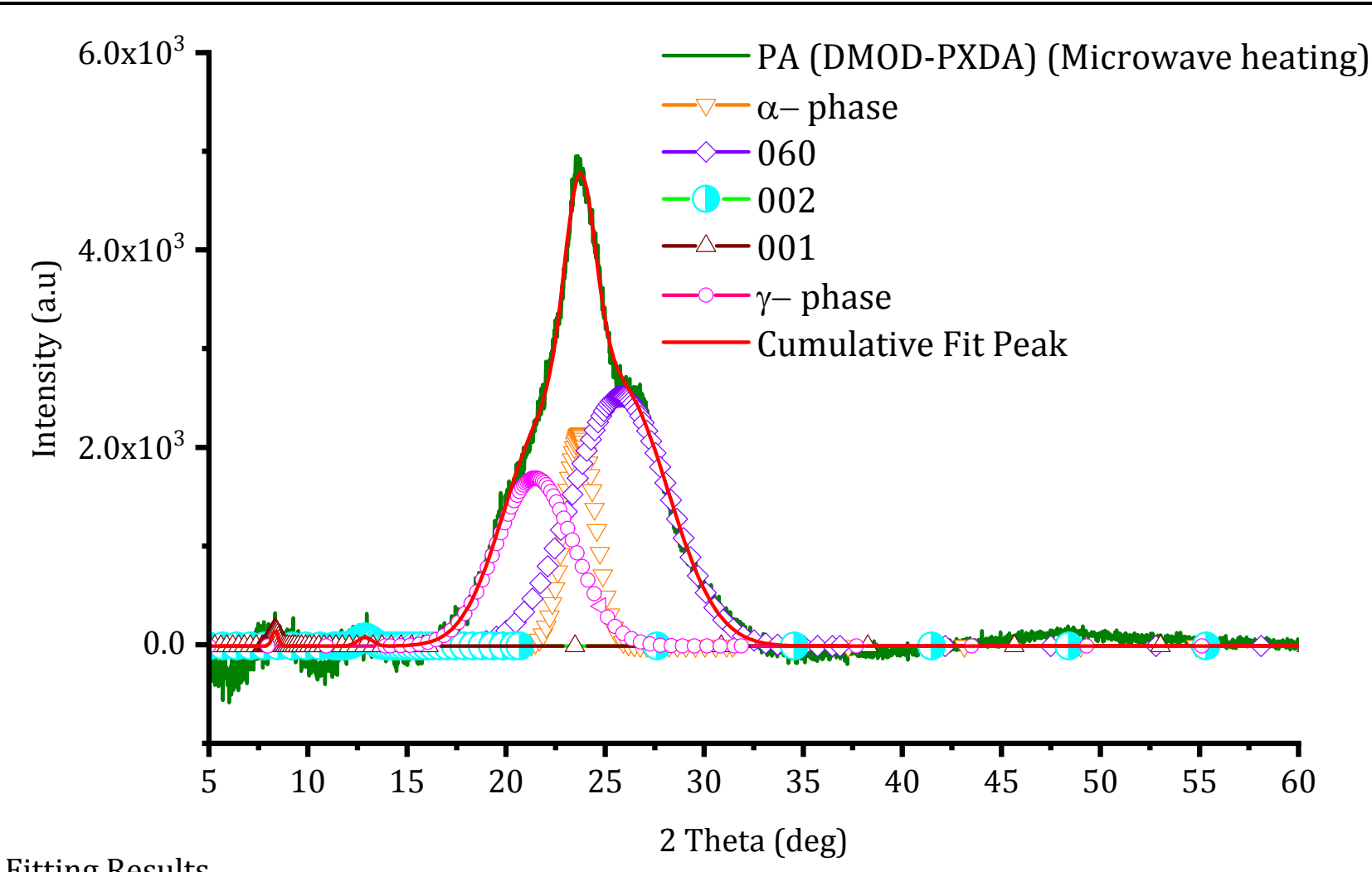

Fitting Results

\begin{tabular}{lllllll}
\hline Peak Index & Peak Type & Area Intg & FWHM & Max Height & Center Grvty & Area IntgP \\
1. & Gaussian & 4195.46548 & 1.83246 & 2150.86111 & 23.73322 & 14.88414 \\
2. & Gaussian & 15516.22319 & 5.75777 & 2531.62733 & 25.78768 & 55.04649 \\
3. & Gaussian & 83.5105 & 0.87839 & 89.31421 & 12.88573 & 0.29627 \\
4. & Gaussian & 63.08515 & 0.35295 & 167.91327 & 8.34221 & 0.22381 \\
5. & Gaussian & 8329.20403 & 4.59603 & 1702.5057 & 21.46735 & 29.54929
\end{tabular}

Figure S8. The profile fittings of biobased MH-PA (DMOD-PXDA).

Peaks:

1- $\alpha$-phase, 2-060, 3-002, 4-001, 5- $\gamma$-phase 


$$
x_{c, W A X D}=\left(\frac{\sum A_{\text {Crystal }}}{\sum A_{\text {Crystal }}+\sum A_{\text {Amorphous }}}\right) \times 100=100 \%
$$

\section{Peak Analysis}

\begin{tabular}{|c|c|c|}
\hline \multicolumn{2}{|c|}{ Data Set:[X12812]X12812!DETA"DETA" } & \multirow[t]{2}{*}{ Date:2020-02-13 } \\
\hline BaseLine:BSpline & & \\
\hline $\mathrm{Chi}^{\wedge} 2=4.37107 \mathrm{E}+003$ & Adj. R-Square $=9.91111 \mathrm{E}-001$ & \multirow[t]{2}{*}{ \# of Data Points $=4251$} \\
\hline$S S=1.85377 \mathrm{E}+007$ & Degree of Freedom=4241. & \\
\hline
\end{tabular}

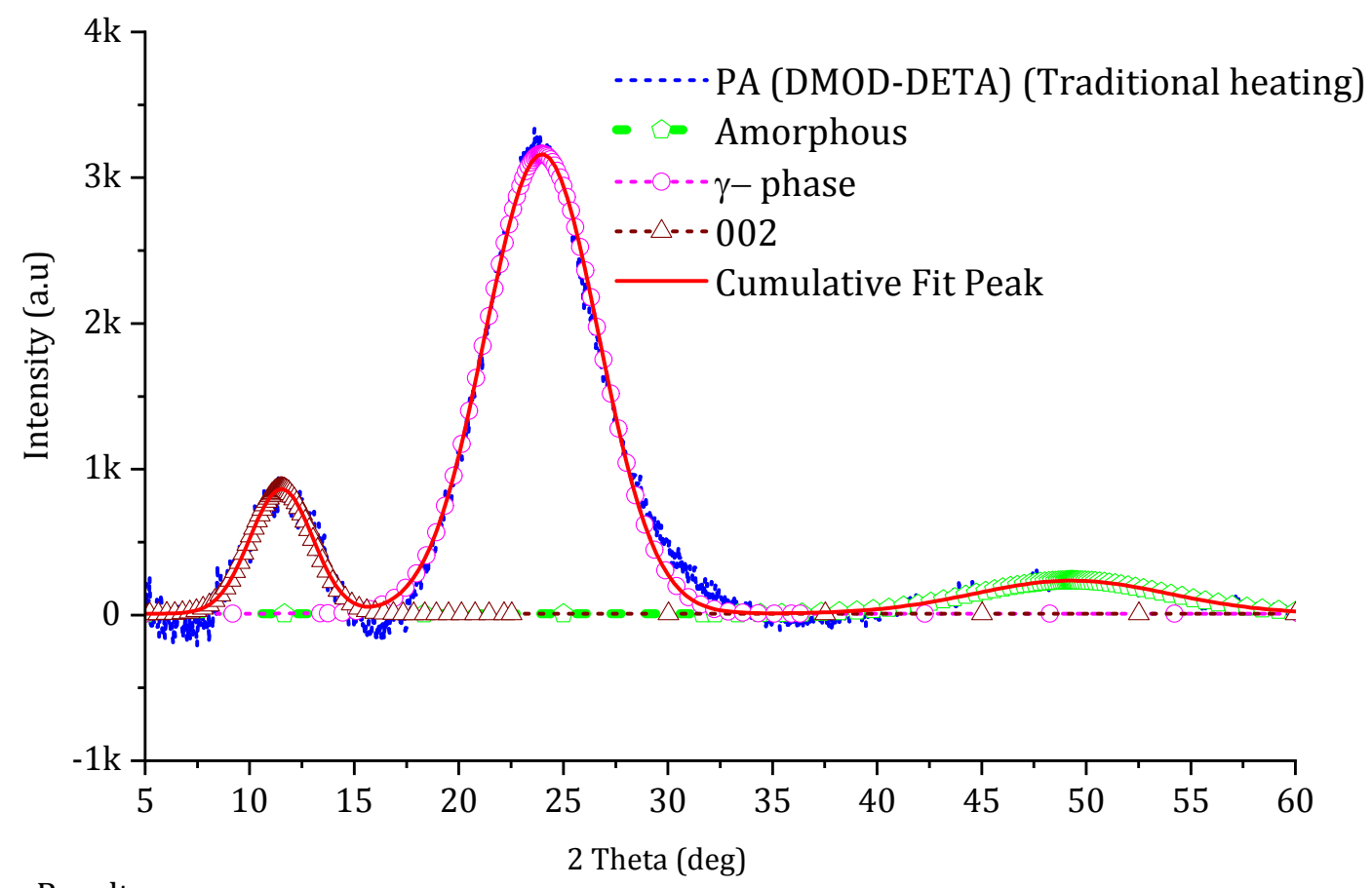

Fitting Results

$\begin{array}{llllll}\text { Peak Index } & \text { Peak Type } & \text { Area Intg } & \text { FWHM } & \text { Max Height } & \text { Center Grvty } \\ 1 . & \text { Gaussian } & 2642.01018 & 10.96213 & 226.41606 & 49.29837 \\ \text { 2. } & \text { Gaussian } & 21454.18072 & 6.39315 & 3152.57162 & 9.67525 \\ 3 . & \text { Gaussian } & 3210.71296 & 3.5206 & 856.7527 & 23.97197 \\ \end{array}$

Figure S9. The profile fittings of biobased TH-PA (DMOD-DETA).

Peaks:

1- Amorphous, 2- $\gamma$-phase, 3- 002,

$$
x_{c, W A X D}=\left(\frac{\sum A_{\text {Crystal }}}{\sum A_{\text {Crystal }}+\sum A_{\text {Amorphous }}}\right) \times 100=\left(\frac{24664.9}{27306.9}\right) \times 100=90.3 \%
$$




\section{Peak Analysis}

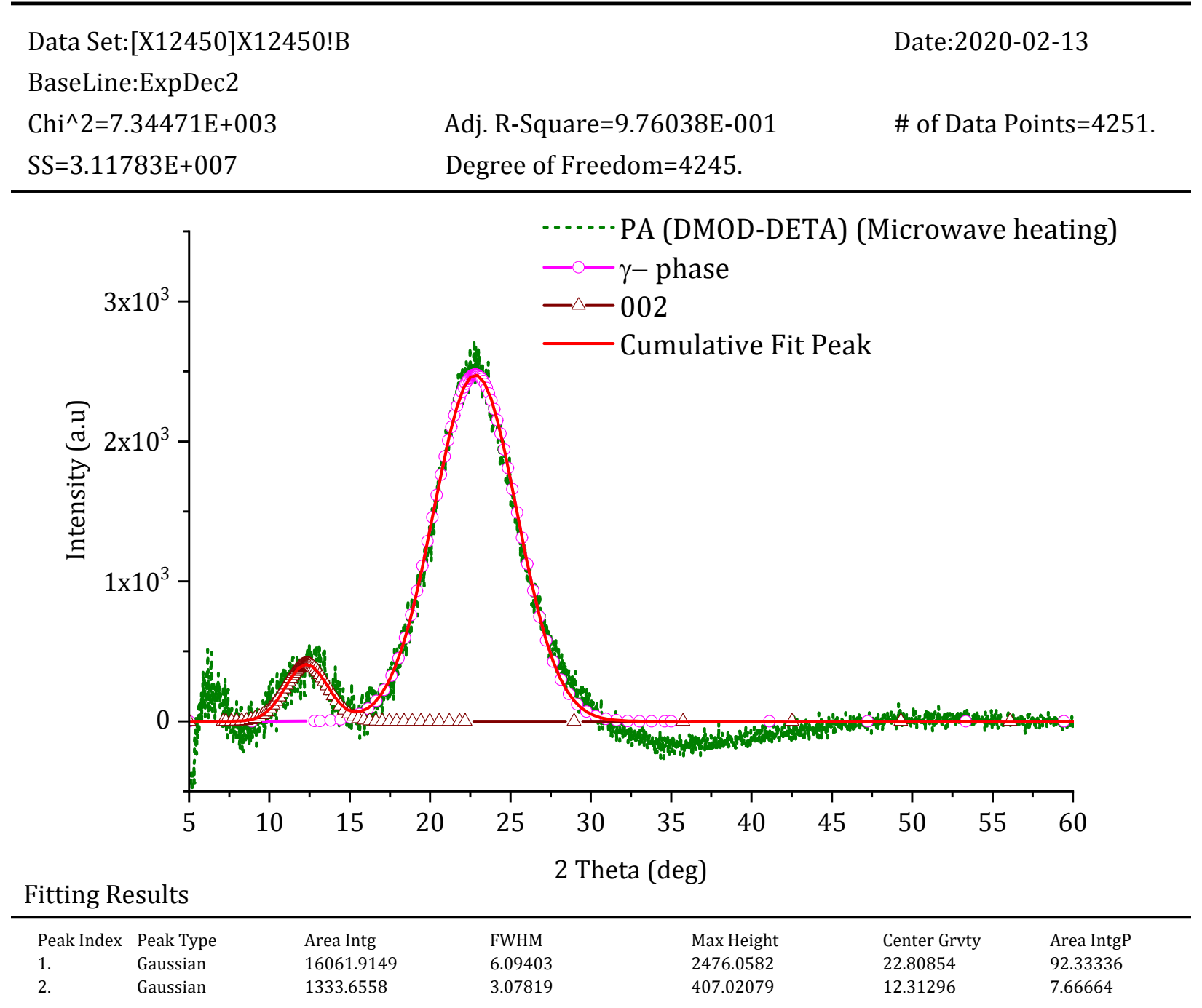

Figure S10. The profile fittings of biobased MH-PA (DMOD-DETA).

Peaks:

1- $\gamma$-phase 2- 002,

$$
x_{c, W A X D}=\left(\frac{\sum A_{\text {Crystal }}}{\sum A_{\text {Crystal }}+\sum A_{\text {Amorphous }}}\right) \times 100=100 \%
$$

References:

(1) Firdaus, M.; Meier, M. A. R. Green Chem. 2013, 15, 370-380.

https://doi.org/10.1039/C2GC36557J 
(2) Girardon, V.; Correia, I.; Tessier, M.; Marchal, E. Eur. Polym. J. 1998, 34, 363-380. https://doi.org/10.1016/S0014-3057(97)00141-9 